\title{
PENGARUH PENGOLAHAN TANAH DAN PENGELOLAAN GULMA TERHADAP POPULASI NEMATODA PARASIT TUMBUHAN PADA TANAMAN UBI KAYU DI KEBUN PERCOBAAN FAKULTAS PERTANIAN UNILA
}

\author{
Widiana Eka Wati, I Gede Swibawa \& Solikhin \\ Jurusan Agroteknologi, Fakultas Pertanian, Universitas Lampung \\ Jl. Prof. Soemantri Brodjonegoro, No. 1, Bandar Lampung 35145 \\ E-mail:widiana_ekawati@yahoo.co.id
}

\begin{abstract}
ABSTRAK
Penelitian ini bertujuan untuk mempelajari pengaruh sistem olah tanah dan pengelolaan gulma serta interaksinya terhadap populasi nematoda parasit tumbuhan pada pertanaman ubi kayu. Penelitian ini dilaksanakan di Kebun Percobaan Lapangan Terpadu Universitas Lampung dari bulan April sampai dengan Oktober 2014. Satuan percobaan berupa petak $4 \mathrm{~m}$ x $4 \mathrm{~m}$ dirancang menggunakan rancangan acak kelompok (RAK) faktorial (2x2) dengan sistem olah tanah sebagai faktor pertama dan pengelolaan gulma sebagai faktor kedua, dengan empat ulangan (kelompok). Sistem olah tanah terdiri dari dua taraf, yaitu olah tanah minimum dan olah tanah intensif. Pengelolaan gulma terdiri dari 2 taraf, yaitu gulma dikendalikan dengan aplikasi herbisida dengan bahan haktif glfosat dan 2,4 D dan gulma dikendalikan secara manual tanpa aplikasi herbisida. Sampel tanah diambil ketika ubi kayu berumur 0 bulan sebelum tanam (0 BST) dan 3 bulan setelah tanam (3 BST). Nematoda diekstraksi menggunakan metode penyaringan dan sentrifugasi menggunakan larutan gula, kemudian diidentifikasi sampai pada tingkat genus berdasarkan ciri morfologinya. Hasil penelitian menunjukan bahwa populasi seluruh nematoda dan nematoda parasit tumbuhan dipengaruhi oleh perlakuan sistem olah tanah ketika tanaman ubi kayu berumur 0 BST, tetapi populasi tersebut tidak dipengaruhi perlakuan olah tanah ketika tanaman ubi kayu berumur 3 BST. Populasi genus Radopholus dipengaruhi oleh perlakuan sistem olah tanah ketika tanaman ubi kayu berumur 0 BST, dan populasi genus Hoplolaimus dipengaruhi oleh perlakuan sistem olah tanah ketika tanaman ubi kayu berumur 3 BST. Populasi seluruh nematoda, nematoda parasit tumbuhan, dan genus nematoda parasit tumbuhan tidak dipengaruhi oleh perlakuan pengelolaan gulma dan interaksinya dengan perlakuan sistem olah tanah baik ketika tanaman ubi kayu berumur 0 BST maupun ketika tanaman ubi kayu berumur 3 BST.
\end{abstract}

Kata kunci : nematoda parasit tumbuhan, pengelolaan gulma, sistem olah tanah

\section{PENDAHULUAN}

Ubi kayu merupakan tanaman sumber bahan pangan, kandungan karbohidrat pada umbi tanaman ini tinggi. Permintaan ubi kayu akan terus meningkat seiring dengan pengembangan energi alternatif bioetanol sebagai pengganti minyak bumi yang semakin habis. Pada tahun 2013 total produksi ubikayu di Indonesia mencapai 23.824.008 ton dengan luas lahan1.061.254 ha. Total produksi ubikayu Provinsi Lampung pada tahun 2013 mencapai 8.237.627 ton dengan luas panen sebesar 314.607 ha (BPS, 2014). Peningkatan produktivitas ubikayu dapat dilakukan dengan menerapkan sistem budidaya yang tepat salah satunya adalah pengolahan tanah. Menurut Rachman dkk. (2004) pengolahan tanah meliputi berbagai kegiatan fisik dan mekanik terhadap tanah yang bertujuan untuk membuat media perakaran tanaman lebih baik. Namun, tanah yang diolah dengan intensitas tinggi secara terus- menerus akan mengalami penurunan produktivitas, memicu erosi, struktur buruk, dan penurunan kandungan bahan organik. Untuk dapat mempertahankan kondisi tanah tetap baik dapat dilakukan dengan menerapkan sistem olah tanah konservasi (OTK).

Dalam sistem OTK pembongkaran atau pembalikan tanah dikurangi, sisa-sisa tanaman digunakan sebagai mulsa, dan kadang-kadang disertai dengan penggunaan herbisida untuk menekan pertumbuhan gulma. Kelebihan penerapan sistem OTK dalam penyiapan lahan adalah meningkatkan kandungan bahan organik tanah, meningkatkan ketersediaan air di dalam tanah, memperbaiki kegemburan tanah, mengurangi erosi tanah, dan meningkatkan aktivitas biota tanah termasuk nematoda (Rachman dkk., 2004).

Banyak jenis nematoda parasit tumbuhan berasosiasi dengan tanaman ubikayu (Bridge dkk., 2005). Nematoda adalah biota tanah yang sangat peka terhadap gangguan lingkungan di dalam tanah. Faktor- faktor 
seperti kelembaban, suhu dan faktor fisik tanah sangat mempengaruhi aktivitas nematoda (Sastrosuwignyo, 1990). Selain itu, keberadaan gulma juga mempengaruhi aktivitas nematoda karena dapat menjadi inang bagi nematoda parasit tumbuhan serta perakaran gulma yang berasosiasi dengan mikroba tanah akan menguntungkan bagi nematoda hidup bebas. Penerapan sistem olah tanah dan pengelolaan gulma dapat mempengaruhi baik faktor fisik tanah maupun keberadaan gulma yang dapat mempengaruhi aktivitas nematoda.

Umumnya pada pertanaman ubi kayu diterapkan sistem olah tanah intensif dan penggunaan herbisida untuk mengendalikan gulma. Belum diketahui bagaimana pengaruh sistem olah tanah minimum dan pengendalian gulma secara manual terhadap komunitas nematoda. Oleh karena itu, penelitian mengenai hal ini perlu dilakukan. Penelitian ini bertujuan untuk mempelajari pengaruh sistem olah tanah dan pengelolaan gulma serta interaksi keduanya terhadap populasi nematoda parasit tumbuhan pada pertanaman ubi kayu.

\section{BAHAN DAN METODE}

Penelitian ini merupakan bagian dari penelitian jangka panjang kerjasama Unila dengan Yokohama National University Jepang yang dilaksanakan di Kebun Percobaan Lapangan Terpadu Universitas Lampung. Sampel tanah diambil pada petak-petak percobaan dan proses laboratorium dilakukan di Laboratorium Hama dan Penyakit Tumbuhan, Fakultas Pertanian, Universitas Lampung dari bulan April sampai dengan Oktober 2014.

Perlakuan dalam percobaan disusun dalam rancangan acak kelompok (RAK) faktorial (2x2). Faktor pertama adalah pengolahan tanah yang terdiri dari dua taraf yaitu olah tanah intensif (OTI) dan olah tanah minimum (OTM). Faktor kedua adalah pengelolaan gulma dengan dua taraf yaitu gulma dikendalikan dengan aplikasi herbisida glifosat dan 2,4 D dan gulma dikendalikan secara manual, tanpa aplikasi herbisida. Lahan dibagi menjadi 4 blok dan tiap blok dibagi menjadi 4 petak dengan ukuran tiap petak $4 \mathrm{~m} \mathrm{x} 4 \mathrm{~m}$.

Pengambilan sampel tanah dilakukan dua kali yaitu pada bulan April dan bulan Agustus 2014. Ketika pengambilan sampel pertama ubikayu belum ditanam (0 BST), lahan masih ditumbuhi jagung yang sudah siap dipanen. Pengambilan sampel kedua dilakukan bulan Agustus yaitu ketika tanaman ubi kayu telah berumur 3 bulan setelah tanam (3 BST). Dari setiap petak percobaan, sampel tanah diambil pada 5 titik sub sampel secara diagonal dengan menggunakan sekop. Sampel tanah diambil sampai kedalaman $20 \mathrm{~cm}$ dan kemudian dicampur sebagai sampel komposit. Masing-masing sampel dimasukkan ke dalam kantung plastik dan diberi label. Sampel tanah diambil pada 5 titik antara lain 4 titik di sudut petak dan 1 titik di titik pusat petak.

Metode ekstraksi nematoda dari tanah yang digunakan adalah metode penyaringan dan sentrifugasi dengan larutan gula terhadap $300 \mathrm{cc}$ sampel tanah (Gafur dan Swibawa, 2004). Nematoda difiksasi dengan larutan golden X sehingga nematoda berada pada larutan formalin 3\%. Populasi nematoda dihitung dengan cara mengambil suspensi sekitar $3 \mathrm{ml}$ dari $10 \mathrm{ml}$ sampai seluruh suspensi habis. Identifikasi nematoda berdasarkan ciri-ciri morfologi dilakukan terhadap 100 nematoda yang diambil secara acak. Identifikasi sampai tingkat genus nematoda berpedoman pada buku Goodey (1963); Mai dan Lyon (1975); Smart dan Nguyen (1988), kemudian dikonfirmasikan kepada dosen pembimbing. Populasi seluruh nematoda, popolasi kelompok nematoda parasit tumbuhan, dan populasi tiap genus nematoda parasit tumbuhan dianalisis ragam dengan menggunakan Uji F $(\alpha=0,05)$.

\section{HASIL DAN PEMBAHASAN}

\section{Populasi Seluruh Nematoda dan Nematoda} Parasit Tumbuhan. Hasil analisis ragam terhadap populasi seluruh nematoda dan kelompok nematoda parasit tumbuhan yang disajikan pada Tabel 1 menunjukan bahwa ketika tanaman ubikayu berumur 0 BST atau sebelum ditanam ubikayu, perlakuan pengolahan tanah nyata berpengaruh terhadap populasi seluruh nematoda (nematoda parasit dan nematoda hidup bebas) serta kelompok nematoda parasit tumbuhan, tetapi pengelolaan gulma dan interaksinya dengan pengolahan tanah tidak nyata berpengaruh terhadap populasi nematoda tersebut. Populasi seluruh nematoda pada petak dengan perlakuan olah tanah minimum (OTM) mencapai 322,5 individu per $300 \mathrm{cc}$ tanah, populasi ini nyata $(\mathrm{P}<0,05)$ lebih tinggi dibandingkan dengan populasi seluruh nematoda pada petak dengan perlakuan olah tanah intensif (OTI) yaitu 84,7 individu per $300 \mathrm{cc}$ tanah. Populasi kelompok nematoda parasit tumbuhan pada petak dengan perlakuan olah tanah minimum (OTM) mencapai 247,4 individu per $300 \mathrm{cc}$ tanah nyata $(\mathrm{P}<0,05)$ lebih tinggi dibandingkan dengan populasi kelompok nematoda parasit tumbuhan ini pada petak dengan perlakuan OTI yaitu 63,7 individu per 300 cc tanah. Utomo (2012) menyatakan bahwa sistem OTI dapat menurunkan bahan organik tanah, akibatnya OTI akan menurunkan komunitas dan aktivitas biota tanah termasuk nematoda. 
Tabel 1. Nilai F hitung analisis ragam pengaruh pengolahan tanah dan pengelolaan gulma terhadap populasi seluruh nematoda dan kelompok nematoda parasit tumbuhan

\begin{tabular}{lcccc}
\hline & \multicolumn{2}{c}{0 BST } & \multicolumn{2}{c}{3 BST } \\
\cline { 2 - 5 } \multicolumn{1}{c}{ Perlakuan } & $\begin{array}{c}\text { Populasi } \\
\text { Seluruh } \\
\text { Nematoda }\end{array}$ & $\begin{array}{c}\text { Populasi } \\
\text { Nematoda Parasit } \\
\text { Tumbuhan }\end{array}$ & $\begin{array}{c}\text { Populasi } \\
\text { Seluruh } \\
\text { Nematoda }\end{array}$ & $\begin{array}{c}\text { Populasi } \\
\text { Nematoda Parasit } \\
\text { Tumbuhan }\end{array}$ \\
\hline Kelompok & $4,22^{*}$ & $3,84 \mathrm{tn}$ & $2,89 \mathrm{tn}$ & $3,18 \mathrm{tn}$ \\
Pengolahan tanah (t) & $9,05^{*}$ & $5,20^{*}$ & $0,19 \mathrm{tn}$ & $0,04 \mathrm{tn}$ \\
Pengelolaan gulma (h) & $0,00 \mathrm{tn}$ & $0,76 \mathrm{tn}$ & $3,79 \mathrm{tn}$ & $2,68 \mathrm{tn}$ \\
Interaksi (t x h) & $0,02 \mathrm{tn}$ & $3,84 \mathrm{tn}$ & $2,89 \mathrm{tn}$ & $3,18 \mathrm{tn}$ \\
\hline
\end{tabular}

Keterangan: $\mathrm{tn}=$ tidak berbeda nyata pada taraf $5 \% ; *=$ nyata pada taraf $5 \% ; 0 \mathrm{BST}=$ nol bulan sebelum tanam; $3 \mathrm{BST}=$ tiga bulan setelah tanam; data yang diolah merupakan data transformasi $\sqrt{\mathrm{x}}+1$.

Ketika tanaman ubi kayu berumur 0 BST, populasi seluruh nematoda pada petak dengan perlakuan pengelolaan gulma dengan penyemprotan herbisida mencapai 197,4 individu per $300 \mathrm{cc}$ tanah, tidak nyata berbeda dengan populasi seluruh nematoda pada petak dengan perlakuan pengelolaan gulma secara dibabat tanpa penyemprotan herbisida yaitu 209,9 individu per 300 cc tanah. Populasi kelompok nematoda parasit tumbuhan pada petak dengan perlakuan pengelolaan gulma dengan penyemprotan herbisida mencapai 160,4 individu per $300 \mathrm{cc}$ tanah, tidak nyata berbeda dengan populasi kelompok nematoda parasit tumbuhan pada petak dengan perlakuan pengelolaan gulma secara dibabat tanpa penyemprotan herbisida yaitu 150,5 individu per $300 \mathrm{cc}$ tanah. Hal ini kemungkinan disebabkan pengaruh pengelolaan gulma dengan penyemprotan herbisida tidak segera tampak, pengaruh herbisida mungkin akan tampak bila penyemprotan herbisida berlangsung lama dan dilakukan terusmenerus.

Ketika tanaman ubi kayu berumur 3 bulan setelah tanam (3 BST) pengaruh semua perlakuan terhadap populasi seluruh nematoda dan kelompok nematoda parasit tumbuhan tidak nyata. Ketika tanaman ubi kayu berumur 3 BST populasi seluruh nematoda pada petak dengan perlakuan OTM sebesar 174,7 individu per 300 cc tanah, tidak nyata berbeda dengan populasi seluruh nematoda pada petak dengan perlakuan OTI yaitu 169,7 individu per $300 \mathrm{cc}$ tanah. Populasi kelompok nematoda parasit tumbuhan pada petak dengan perlakuan OTM sebesar 91,7 individu per $300 \mathrm{cc}$ tanah tidak nyata berbeda dengan populasi kelompok nematoda parasit tumbuhan pada petak dengan perlakuan OTI yaitu 122,8 individu per $300 \mathrm{cc}$ tanah. Kemungkinan tiadanya pengaruh pengolahan tanah ini berkaitan dengan keberadaan bahan organik dan kadar air tanah.
Berdasarkan hasil penelitian Burhannudin (2014), jumlah bahan organik tanah pada petak percobaan OTM ketika tanaman ubikayu berumur 3 BST tidak berbeda dengan bahan organik pada petak OTI.

Ketika tanaman ubikayu berumur 3 BST populasi seluruh nematoda pada petak dengan perlakuan pengelolaan gulma dengan penyemprotan herbisida sebesar 133,1 individu per $300 \mathrm{cc}$ tanah tidak berbeda dengan populasi seluruh nematoda pada petak dengan perlakuan pengelolaan gulma secara dibabat tanpa penyemprotan herbisida yaitu 211,4 individu per $300 \mathrm{cc}$ tanah. Populasi kelompok nematoda parasit tumbuhan pada petak dengan perlakuan pengelolaan gulma dengan penyemprotan herbisida sebesar 80,4 individu per 300 cc tanah, tidak berbeda dengan populasi kelompok nematoda parasit tumbuhan pada petak dengan perlakuan pengelolaan gulma secara dibabat tanpa penyemprotan herbisida yaitu 134,0 individu per $300 \mathrm{cc}$ tanah. Perlakuan pengelolaan gulma dengan penyemprotan herbisida pada pertanaman ubikayu tidak nyata mempengaruhi populasi nematoda parasit tumbuhan dan seluruh nematoda. Hal ini kemungkinan karena dampak negatif penyemprotan herbisida umumnya baru tampak ketika residu bahan aktif herbisida telah terakumulasi di dalam tanah dalam jumlah yang besar dan telah mencapai level yang menyebabkan keracunan terhadap nematoda di dalam tanah.

Populasi Genus Nematoda Parasit Tumbuhan. Ketika ubi kayu berumur 0 BST ditemukan 18 genus nematoda parasit tumbuhan dan ketika ubi kayu berumur 3 BST ditemukan 14 genus nematoda parasit tumbuhan. Beberapa genus yang ditemukan ketika ubi kayu berumur 0 BST yaitu Tylenchida MG, Longidorella, Tylenchulus, Radopholoides, Tetylenchus, dan Meloidodera tidak ditemukan ketika ubi kayu berumur 3 BST. Satu genus yaitu 
Paralongidorus yang tidak ditemukan ketika ubi kayu 0 BST, ditemukan pada ubi kayu umur 3 BST. Nematoda parasit tumbuhan yang dominan ketika tanaman ubi kayu berumur 0 BST dan 3 BST, yaitu Pratylenchus, Helicotylenchus, dan Radopholus. Pratylenchus dan Helicotylenchus merupakan nematoda peluka akar yang tersebar luas (kosmopolitan), demikian juga Radopholus yang merupakan nematoda pelubang akar. Pratylenchus merupakan nematoda parasit tumbuhan yang menimbulkan masalah serius pada pertanaman ubi kayu di berbagai negara. Nematoda $P$. bracyurus dan $H$. erythernae kerap melimpah dan berasosiasi dengan akar tanaman ubi kayu dan $P$. brachyurus merupakan nematoda parasit penting yang menyerang tanaman ubi kayu, dapat ditemukan di beberapa daerah di dunia sehingga mungkin akan menjadi nematoda terpenting berikutnya setelah nematoda puru akar Melidogyne incognita (Bridge dkk, 2005; Coyne, 1994).
Hasil analisis ragam menunjukkan bahwa pengaruh perlakuan pengolahan tanah dan pengelolaan gulma serta interaksinya tidak nyata terhadap populasi sebagian besar genus nematoda parasit tumbuhan baik ketika ubi kayu umur 0 BST maupun 3 BST. Pengaruh perlakuan pengolahan tanah hanya nyata terhadap populasi genus Radopholus ketika tanaman ubi kayu berumur 0 BST dan genus Hoplolaimus ketika tanaman ubi kayu berumur 3 BST. Pengaruh perlakuan pengelolaan gulma tidak nyata terhadap populasi genus nematoda parasit tumbuhan baik ketika tanaman ubi kayu berumur 0 BST maupun ubikayu berumur 3 BST, begitu pula pengaruh interaksi olah tanah dengan pengelolaan gulma (Tabel 2).

Ketika tanaman ubi kayu berumur 0 BST populasi genus Radopholus pada petak dengan perlakuan olah tanah minimum (OTM) mencapai 51,9 individu/300 cc tanah, populasi ini nyata $(\mathrm{P}<0,05)$ lebih tinggi dibandingkan dengan populasi genus Radopholus pada

Tabel 2. Nilai $\mathrm{F}$ hitung analisis ragam pengaruh pengolahan tanah dan pengelolaan gulma terhadap populasi genus nematoda parasit tumbuhan

\begin{tabular}{|c|c|c|c|c|c|c|}
\hline \multirow{2}{*}{ Nematoda Parasit } & \multicolumn{2}{|c|}{ Pengolahan tanah $(\mathrm{t})$} & \multicolumn{2}{|c|}{ Pengelolaan gulma (h) } & \multicolumn{2}{|c|}{ Interaksi (t xh) } \\
\hline & $0 \mathrm{BST}$ & $3 \mathrm{BST}$ & $0 \mathrm{BST}$ & $3 \mathrm{BST}$ & $0 \mathrm{BST}$ & $3 \mathrm{BST}$ \\
\hline Paralongidorus & - & $1,00 \mathrm{tn}$ & - & $1,00 \mathrm{tn}$ & - & $1,00 \mathrm{tn}$ \\
\hline Radopholus & $5,95^{*}$ & $0,69 \mathrm{tn}$ & $0,90 \mathrm{tn}$ & $2,85 \mathrm{tn}$ & $0,17 \mathrm{tn}$ & $0,30 \mathrm{tn}$ \\
\hline Pratylenchus & $4,40 \mathrm{tn}$ & $0,28 \mathrm{tn}$ & $0,31 \mathrm{tn}$ & $1,16 \mathrm{tn}$ & $0,00 \mathrm{tn}$ & 0,05 tn \\
\hline Helicotylenchus & $0,02 \mathrm{tn}$ & $0,06 \mathrm{tn}$ & $0,25 \mathrm{tn}$ & $3,86 \mathrm{tn}$ & $0,41 \mathrm{tn}$ & $1,58 \mathrm{tn}$ \\
\hline Meloidoyne J2 & $0,45 \mathrm{tn}$ & $3,20 \mathrm{tn}$ & $0,96 \mathrm{tn}$ & $2,08 \mathrm{tn}$ & $1,57 \mathrm{tn}$ & $0,71 \mathrm{tn}$ \\
\hline Tylenchus & $1,24 \mathrm{tn}$ & $0,02 \mathrm{tn}$ & $0,02 \mathrm{tn}$ & $3,62 \mathrm{tn}$ & $0,01 \mathrm{tn}$ & $0,40 \mathrm{tn}$ \\
\hline Tylenchida MG & $0,12 \mathrm{tn}$ & - & $4,16 \mathrm{tn}$ & - & $1,79 \mathrm{tn}$ & - \\
\hline Longidorus & $4,05 \mathrm{tn}$ & $4,83 \mathrm{tn}$ & $1,46 \mathrm{tn}$ & $0,33 \mathrm{tn}$ & $0,49 \mathrm{tn}$ & 0,33 tn \\
\hline Criconemoides & $2,62 \mathrm{tn}$ & $1,00 \mathrm{tn}$ & $1,62 \mathrm{tn}$ & $1,00 \mathrm{tn}$ & $1,03 \mathrm{tn}$ & $1,00 \mathrm{tn}$ \\
\hline Longidorella & $0,56 \mathrm{tn}$ & - & $1,35 \mathrm{tn}$ & - & $0,56 \mathrm{tn}$ & - \\
\hline Hoplolaimus & $0,30 \mathrm{tn}$ & $6,03^{*}$ & $0,30 \mathrm{tn}$ & $0,08 \mathrm{tn}$ & $0,28 \mathrm{tn}$ & 0,25 th \\
\hline Xiphinema & $1,69 \mathrm{tn}$ & $0,90 \mathrm{tn}$ & $0,13 \mathrm{tn}$ & $3,74 \mathrm{tn}$ & $0,13 \mathrm{tn}$ & 6,48 th \\
\hline Tylenchulus $\mathrm{J} 2$ & $0,34 \mathrm{tn}$ & - & $0,34 \mathrm{tn}$ & - & $1,53 \mathrm{tn}$ & - \\
\hline Rotylenchulus & $2,44 \mathrm{tn}$ & $2,59 \mathrm{tn}$ & $0,35 \mathrm{tn}$ & $3,63 \mathrm{tn}$ & $0,59 \mathrm{tn}$ & $2,59 \mathrm{tn}$ \\
\hline Hemicriconemoides & $0,16 \mathrm{tn}$ & $0,16 \mathrm{tn}$ & $0,16 \mathrm{tn}$ & $0,42 \mathrm{tn}$ & $2,53 \mathrm{tn}$ & 1,33 tn \\
\hline Radopholoides & $1,00 \mathrm{tn}$ & - & $1,00 \mathrm{tn}$ & - & $1,00 \mathrm{tn}$ & - \\
\hline Rotylenchus & $4,81 \mathrm{tn}$ & $1,00 \mathrm{tn}$ & $0,34 \mathrm{tn}$ & $1,00 \mathrm{tn}$ & $0,34 \mathrm{tn}$ & $1,00 \mathrm{tn}$ \\
\hline Tetylenchus & $0,07 \mathrm{tn}$ & - & $0,07 \mathrm{tn}$ & - & $1,75 \mathrm{tn}$ & - \\
\hline Ditylenchus & $1,00 \mathrm{tn}$ & $1,00 \mathrm{tn}$ & $1,00 \mathrm{tn}$ & $1,00 \mathrm{tn}$ & $1,00 \mathrm{tn}$ & $1,00 \mathrm{tn}$ \\
\hline Meloidodera & $2,66 \mathrm{tn}$ & - & $2,66 \mathrm{tn}$ & - & $2,66 \mathrm{tn}$ & - \\
\hline
\end{tabular}

Keterangan: : $\mathrm{tn}=$ tidak berbeda nyata pada taraf $5 \% ; *=$ nyata pada taraf $5 \% ; 0 \mathrm{BST}=$ nol bulan sebelum tanam; 3 BST = tiga bulan setelah tanam; - = tidak ditemukan; data yang diolah merupakan data transformasi $\sqrt{\mathrm{x}}+1$. 
petak dengan perlakuan OTI yaitu 2,1 individu per 300cc tanah. Ketika tanaman ubi kayu berumur 3 BST populasi genus Hoplolaimus pada petak dengan perlakuan OTM sebesar 3 individu per $300 \mathrm{cc}$ tanah nyata $(\mathrm{P}<0,05)$ lebih tinggi dibandingkan dengan populasi genus Hoplolaimus pada petak dengan perlakuan OTI yaitu $0,3 \mathrm{individu} / 300 \mathrm{cc}$ tanah. Hal ini kemungkinan karena sifat morfologi kedua genus nematoda tersebut berbeda dengan nematoda lainnya sehingga genus nematoda tersebut dapat bertahan pada perlakuan OTM. Populasi genus Pratylenchus tinggi pada OTM yaitu 100 lebih dari individu per $300 \mathrm{cc}$ tanah, tetapi tidak berbeda dengan genus ini yang hanya sekitar 11 individu per 300 cc tanah pada OTI. Hal ini dapat terjadi karena keragaman data populasi nematoda pada perlakuan OTM sangat tinggi. Populasi genus-genus nematoda parasit tumbuhan pada petak yang pengelolaan gulmanya dengan penyemprotan herbisida tidak berbeda dengan populasi genus nematoda tersebut pada petak yang pengelolaan gulmanya dengan cara dibabat, baik ketika tanaman ubikayu berumur 0 BST maupun ketika tanaman ubi kayu berumur 3 BST.

\section{KESIMPULAN}

Dari hasil penelitian ini dapat disimpulkan bahwa populasi seluruh nematoda dan nematoda parasit tumbuhan dipengaruhi oleh perlakuan sistem olah tanah ketika tanaman ubi kayu berumur 0 BST, tetapi tidak ketika tanaman ubi kayu berumur 3 BST. Populasi genus Radopholus dipengaruhi perlakuan sistem olah tanah ketika tanaman ubi kayu berumur 0 BST, dan populasi genus Hoplolaimus dipengaruhi perlakuan sistem olah tanah ketika tanaman ubikayu berumur 3 BST. Populasi seluruh nematoda, nematoda parasit tumbuhan, dan genus nematoda parasit tumbuhan tidak dipengaruhi oleh perlakuan pengelolaan gulma dan interaksinya dengan perlakuan sistem olah tanah baik ketika tanaman ubi kayu berumur 0 BST maupun ketika tanaman ubi kayu berumur 3 BST.

\section{DAFTAR PUSTAKA}

Badan Pusat Statistik. 2014. Data Produktivitas Ubikayu Indonesia dan Provinsi Lampung. http:// webbeta.bps.go.id/tnmn pgn.php? kat $=3 \& i d$ subyek $=53 \&$ notab $=0$. Diakses tanggal 29 Mei 2014.
Bridge.J., D. L. Coyne and C. K. Kwoseh. 2005. Nematode Parasitic of Tropical Root and Tuber Crops (Excluding Potatoes). In M, Luc., R. A. Skora and J. Bridge (eds). Plant Parasitic Nematodes in Subtropical and Tropical Agriculture. 2nd edition. CABI Publishing. Cambridge USA. P. 221-259.

Burhannudin. 2014. Pengaruh Sistem Olah Tanah dan Herbisida terhadap Kehilangan Unsur Hara dan Bahan Organik Akibat Erosi di Laboratorium Lapangan Terpadu Fakultas Pertanian Universitas Lampung. (Skripsi). Universitas Lampung. Lampung. $42 \mathrm{hlm}$.

Coyne.D.I. 1994. Nematode Pests of Cassava. African Crop Science Journal 2(4): 355-359.

Gafur, A dan I.G. Swibawa. 2004. Methods in Nematodes and Soil Microbe Research for Belowground Bioversity Assessment in F. X. Susilo, A. Gafur, M. Utomo, R. Evizal, S. Murwani, IG. Swibawa (eds.), Conservation and Sustainable Management of Below. Ground Biodiversity in Indonesia, Universitas Lampung. P 117-123.

Goodey, J.B. 1963. Soil and Freshwater Nematodes. Methuen CO. LTD. London. 544 p.

Mai, W. F dan H. H. Lyon. 1975. Pictorial Key to Genera of Plant Parasitic Nematodes. Comstock Publishing Associates, Cornell University Press. 220 p.

Rachman, A, U. Kurnia, dan A. Dariah. 2004. Teknologi Konservasi Tanah pada Lahan Kering Berlereng. Pusat Penelitian dan Pengembangan Tanah dan Agroklimat (Puslitbangtanak). Jawa Barat. Hal 183- 201.

Sastrosuwignyo, S. 1990. Nematologi Tumbuhan. Institut Pertanian Bogor. Bogor. $246 \mathrm{hlm}$.

Smart,G. C and K.B. Nguyen.1988. Illustrated Key for the Identification of Common Nematodes in Florida. University of Florida. Florida. $91 \mathrm{p}$.

Utomo, M. 2012. Tanpa Olah Tanah: Teknologi Pengelolaan Pertanian Lahan Kering. Lempaga Penelitian Universitas Lampung. Bandar Lampung. $110 \mathrm{hlm}$. 